\title{
MENITI SINKRETISME TEKS TANTU PANGGĚLARAN
}

\author{
Turita Indah Setyani \\ Program Studi Sastra Daerah untuk Sastra Jawa \\ Fakultas Ilmu Pengetahuan Budaya Universitas Indonesia \\ Email: turita.indah@gmail.com
}

\begin{abstract}
Tantu Panggělaran (TP) is a work of literature that contains knowledge necessary for human beings to achieve perfection of living which is influenced by Javanese, Hindu (Shivaist), and Buddhist concepts. This research studies syncretism in the text of TP by using the theory of normative multiculturalism. The purpose of this research is to find out how syncretism occurred in people's lives, as recorded in the text of TP. It is hoped this research can benefit the development of Javanese culture in general, and particularly Old Javanese culture from the late Majapahit era. The results show that TP is the implementation of cultural syncretism of Javanese, Hindu (Shivaist), and Buddhist cultures in a positive, mutualistic relationship.
\end{abstract}

Keyword: Tantu Panggělaran, Multiculturalism, Syncretism

\begin{abstract}
ABSTRAK
Tantu Panggělaran (TP) merupakan karya sastra yang berisi pengetahuan bagi manusia untuk mencapai kesempurnaan hidup yang dipengaruhi konsep Jawa, Hindu (Siwa) dan Buddha. Penelitian ini mengkaji sinkretisme dalam teks TP dengan menggunakan teori multikulturalisme normatif. Tujuan penelitian untuk mengetahui bagaimana sinkretisme yang terjadi terhadap kehidupan masyarakat di dalam teks TP. Diharapkan penelitian ini dapat memberikan manfaat terhadap perkembangan budaya Jawa pada umumnya, khususnya budaya Jawa Kuna zaman Majapahit akhir. Hasil penelitian mengungkapkan bahwa karya sastra TP merupakan implementasi sinkretisme budaya Jawa, Hindu (Siwa), Buddha dalam hubungan yang mutualistik dan bersifat positif.
\end{abstract}

Kata Kunci: Tantu Panggělaran, Multikulturalisme, Sinkretisme 


\section{PENGANTAR}

Sinkretisme telah banyak dibicarakan dalam berbagai aspek kehidupan di seluruh dunia, Indonesia pada umumnya, dan dalam kehidupan masyarakat Jawa pada khususnya. Istilah sinkretisme dalam kamus Antropologi (1985: 373) diberi arti sebagai "kombinasi segala unsur dari beberapa agama dan kepercayaan yang berbeda, kemudian terpadu menjadi satu yang kemudian merupakan agama atau kepercayaan versi baru".

Sinkretisme dalam kehidupan masyarakat Jawa merupakan perpaduan, percampuran, dan penyelarasan dua keyakinan atau lebih. Hasil sinkretisme dapat membentuk keyakinan baru atau menomorsatukan keyakinan yang dianggap paling benar. Adapun sinkretisme itu sendiri tidak terlepas dari kenisbian dan bersifat divergen. Dengan kata lain, sinkretik yang terjadi dalam masyarakat Jawa bersifat longgar, adaptif, dan akomodatif. Hal itu termanifestasi dalam kehidupan mistik kejawen sebagai praktek religi masyarakat Jawa yang disebut agama Jawa.

Dalam praktek religi tersebut terdapat dua pihak yang berbeda pendapat, yaitu pihak pertama meyakini adanya pengaruh sinkretik dengan agama-agama lain. Kedua, meyakini bahwa mistik kejawen merupakan milik manusia Jawa yang sudah ada sejak masyarakat Jawa mengenal Tuhan dengan praktek-praktek religinya, memuja para roh dan benda-benda yang dikenal dengan pemujaan animisme dan dinamisme. Akan tetapi sejak zaman Hindu-Buddha berpengaruh di Jawa, terjadilah sinkretisme. Pengaruh tersebut tidak hanya pada masyarakat kecil, tetapi juga dunia kraton dan para priyayi.

Perkembangan pengaruh lebih cepat tercerap disebabkan oleh adanya kitab-kitab yang berisi kisah-kisah mistis. Kitab-kitab tersebut menjadi salah satu media penyebaran sinkretisme yang mempengaruhi pola religi Jawa, antara lain yaitu Tantu Panggělaran, Bhagawat Gita, Bharatayuda, Brahmandapurana, Sutasoma, dan sebagainya (En- draswara, 2006: 73, 78, 80). Dengan demikian, dapat dikatakan bahwa keadaan pola religi Jawa yang ada hingga saat ini merupakan hasil sinkretisme yang terjadi sejak masuknya budaya asing ke Pulau Jawa yang terekam dalam kitab-kitab mistisnya. Oleh karena itu, untuk menelusuri pola religi tersebut, dapat dideteksi melalui kitab-kitab yang tersebar di Pulau Jawa.

Menurut A. H. Johns (1966: 40) untuk mengkaji perubahan relegi haruslah berdasarkan dokumen-dokumen yang relevan dengan periodenya, yaitu masa atau kurun waktu yang sesuai dengan dokumen yang digunakan sebagai korpus penelitian. Dokumen di Jawa yang masih dianggap bertahan hingga saat ini adalah dari periode abad ke15 sampai awal abad ke-16. Pada abad-18 diwakili oleh Serat Centhini. Dua dokumen yang dapat dipastikan tradisi kuna yaitu Tantu Panggělaran (TP) dan Bhimasuci (juga dikenal sebagai Dewaruci). Akan tetapi yang memuat sinkretisme di dalamnya adalah TP. Oleh karena itu TP akan dijadikan bahan kajian sinkretisme pola religi Jawa dengan menggunakan teori multikulturalisme.

Secara garis besar multikulturalisme berkaitan dengan keragaman budaya, adat istiadat, agama atau kepercayaan (religi), identitas, akulturasi, sejarah, relasi kuasa, toleransi, dan lain-lain. Secara etimologi, multikulturalisme berasal dari kata "multi" yang berarti plural, dan "kultural" yang berarti kultur atau budaya, sedangkan "isme" adalah paham atau aliran. Jadi secara sederhana multikulturalisme merupakan paham atau aliran tentang budaya yang plural (Marjani, 2009).

Bhikhu Parekh (2008: 19-21) mengemukakan bahwa sebuah masyarakat yang multikultural merupakan sebuah masyarakat yang meliputi dua atau lebih komunitas kultural. Istilah 'multikultural' mengacu pada kenyataan akan keanekaragaman kultur, sedangkan istilah 'multikulturalisme' mengacu pada sebuah tanggapan normatif atas fakta tersebut. Perbedaan normatif tidak seharusnya dibiarkan mempengaruhi gambaran realitas empiris. Sementara itu, bagi 
Gustiana Isya Marjani (2009) yang mengutip pendapat Rob Reich memberikan rumusan tentang "multikulturalisme normatif" sebagai berikut:

Multikulturalisme normatif berkaitan dengan dasar-dasar moral antara keterkaitan seseorang dalam suatu negara bangsa. Artinya terdapat suatu ikatan moral dari anggota-anggotanya dalam batas-batas negara bangsa untuk melakukan sesuatu sebagaimana yang telah menjadi kesepakatan bersama. Dalam kaitan ini multikultural normatif merupakan suatu kritik sosial dalam membangun keinginan bersama dari suatu kelompok, membangun suatu wadah di dalam pluralitas budaya yang ada dalam komunitas tersebut.

Berdasarkan pandangan tersebut, multikulturalisme normatif menjadi bagian untuk meniti sinkretisme teks Tantu Panggélaran.

TP yang terdiri atas mitos-mitos tentang penciptaan, antara lain manusia pertama di Pulau Jawa, awal mula rumah sebagai tempat tinggal, pekerjaan sebagai mata pencaharian manusia, pakaian, perhiasan, hingga kesempurnaan hidup terjadi. Keseimbangan dalam kehidupan manusia dan alam semesta merupakan hasil sinkretisme yang terjadi dari latar belakang budaya yang berpengaruh pada saat TP diciptakan. Hal itu sekaligus merupakan alam pikiran pengarangnya yang memunculkan berbagai identitas budaya (Jawa, Hindu/Siwa, Buddha).

Berdasarkan edisi teks yang telah dikerjakan oleh Th. Pigeaud (1924), naskah yang dipilih olehnya didasarkan pada kenyataan bahwa naskah itu merupakan satu-satunya di antara tujuh naskah yang memiliki kolofon dan berangka tahun. Kolofon tersebut dalam transliterasi Pigeaud berbunyi:

Iti sang hyang Tantu panglaran, kagaduhana de sang mataki-taki, kabuyutan ing sang Yawadipa, caturpakandan, caturpaksa, kabuyutan ring Nanggaparwwata. Muwah tanpasasangkala, mulanikang manusa Jawa, duk durung sang hyang Mahameru tka ring Jawa, sawusira tibeng Jawa: mangkana nimitanya tanpasasangkala, reh yan ing purwwa. Tlaç [s] inurat sang hyang Tantu panglaran ring karang kabhujangggan Kutritusan, dina u(manis) bu(dha) madangsya, titi caci kaca, rah 7, tenggek 5, rsi pandawa buta tunggal: 1557 (Pigeaud, 1924: 128)

Kutipan tersebut memaparkan bahwa penulis/penyalin teks ini tinggal di suatu karang kabhujanggan, yaitu suatu lokasi khusus tempat tinggal para bhujangga (penyandang tugas keagamaan), Kutritusan namanya. Dinyatakan pula bahwa kitab ini hendaknya menjadi milik mereka (para pertapa) yang "menjalani upaya (ritual keagamaan) dengan penuh perhatian" (mataki-taki) di tempat-tempat suci kuna (kabuyutan) di Jawa. Sedyawati (2001: 2) menegaskan bahwa dari hasil pembacaan terhadap seluruh teks TP sama sekali tidak mengacu atau menunjukkan pernyataan keterlibatan apapun dengan kalangan raja dan bangsawan.

Oleh karena itu, meskipun disebutkan beberapa nama raja dan daerah/wilayahnya, namun gambaran tersebut merupakan pelengkap dalam proses penciptaan dan keseimbangan Pulau Jawa. Hal itu dapat dianggap bahwa TP dibuat di dan untuk kalangan keagamaan di luar lingkungan kehidupan kraton. Bahkan nilai-nilai dan norma-norma yang berlaku di dalamnya berkaitan dengan kehidupan para pertapa atau golongan rohaniwan.

Pada kolofon tertulis angka tahun 1557 Çaka yaitu 1635 M, menunjukkan bahwa TP berada pada periode abad ke-17. Akan tetapi, tidak dinyatakan apakah tahun tersebut merupakan tahun penulisan atau penyalinan naskah. Untuk selanjutnya waktu penulisan TP tidak menjadi pusat perhatian kajian ini. Meskipun demikian angka tahun tersebut paling tidak menunjukkan bahwa TP memiliki eksistensi pada periodesasi zamannya di Pulau Jawa, berkaitan dengan sinkretisme yang termuat di dalamnya. Oleh karena itu, TP menjadi penting diteliti lebih dalam untuk mengetahui bagaimana sinkretisme sebagai salah satu bagian dari multikulturalisme itu terjadi. Berikut pembahasan multikulturalisme yang terdapat di dalamnya, sehingga dapat diketahui dengan jelas 
tujuan penulisan TP dalam bentuk sinkretisme tersebut.

\section{Multikulturalisme dalam Teks TP}

Menilik perkembangan agama Buddha di Indonesia, Widyadharma (1999: 5-6) menyatakan bahwa:

pada tahun 672, I-tsing, seorang sarjana agama Buddha dari Tiongkok, melakukan perjalanan untuk berziarah ke tempat-tempat suci agama Buddha di India. Ketika perjalanan pulangnya, tahun 685 , ia singgah di Sriwijaya dan tinggal di sana hingga 10 tahun untuk mempelajari dan menyalin buku-buku suci agama Buddha. Pada saat itu Sriwijaya merupakan pusat ilmu dan kebudayaan Buddha, sehingga menjadi mercusuar agama Buddha di Asia Tenggara yang memancarkan cahaya budaya manusia yang cemerlang. I-tsing pun banyak menceritakan tentang agama Buddha di Sriwijaya ini. Pada tahun 775-850 di daerah Bagelen dan Yogyakarta berkuasalah raja-raja dari Wangsa Sailendra yang memeluk agama Buddha. Zaman ini adalah zaman keemasan bagi Mataram. Ilmu pengetahuan, terutama ilmu pengetahuan tentang agama Buddha sangat maju. Demikian juga keseniannya, terutama seni pahat mencapai taraf yang sangat tinggi dengan adanya pembangunan candi-candi: Kalasan, Sewu, dan Borobudur, Pawon, Mendhut yang memiliki konsep makrokosmos sebagai dasar bangunan candi. Perkembangan sejarah selanjutnya, setelah raja Samaratungga wafat, Mataram kembali diperintah oleh raja-raja dari Wangsa Sanjaya yang beragama Hindu, namun agama Buddha dan Hindu dapat berkembang terus berdampingan dengan rukun dan damai. Keadaannya masih terus demikian hingga di masa pemerintahan rajaraja Majapahit tahun 1292-1476. Toleransi keagamaan dijaga baik-baik, sehingga tidak ada pertentang agama.

Menurut Hariani Santiko (Kompas, 14 Januari 2009) Majapahit adalah kerajaan agro-maritim yang multikultural. Perdagangan terjadi, baik lokal, antarpulau atau internasional yang melibatkan pedagang dari berbagai daerah. Hal ini menciptakan kondisi multikultural di Majapahit yang menjadi situs pertemuan dan percampuran ane- ka unsur budaya "pendatang" dan lokal. Kondisi multikultural ini terjalin dengan proses-proses politik di Majapahit, sejalan dengan "proyek politik Nusantara" Gajahmada untuk memperluas dan menyatukan wilayah Majapahit, yang dicetuskan sebagai "Sumpah Palapa" di hadapan Ratu Tribhuwanotunggadewi, ibu Raja Hayam Wuruk. Dinamika politik-budaya ini dipertahankan, khususnya oleh Raja Hayam Wuruk yang mempertahankan hegemoni Majapahit meski harus bekerja sendiri selama 25 tahun.

Hayam Wuruk dan raja-raja Majapahit lainnya amat menghargai multiagama yang berkembang saat itu. Pengaruh agama yang masuk ke dalam suatu wilayah, dalam hal ini Jawa, berkaitan dengan pengaruh politik dan kebudayaan yang menyertainya sekaligus. Akan tetapi dengan wafatnya Hayam Wuruk tahun 1389, kerajaan Majapahit memudar karena ada konflik internal, perebutan kekuasaan. Meski demikian, kondisi multikultural tetap dipertahankan, khususnya dalam bidang agama. Oleh karena itu, pada masa Majapahit golongan agamawan memiliki kedudukan penting karena mereka turut berperan dalam susunan pejabat tinggi kerajaan, yaitu sebagai pemimpin tertinggi dalam agama Siwa dan Buddha. Bahkan mereka juga menduduki jabatan sebagai hakim agung yang membantu raja dalam memutuskan suatu masalah. Raja dan para pejabat negara tidak diperkenankan untuk campur tangan dalam hal keagamaan (Munandar, 1990: 139, 147). Dengan kata lain, kehidupan keagamaan menjadi perhatian khusus dalam masyarakat Majapahit.

Hal itulah yang melibatkan karya-karya sastra turut mengungkapkan kepentingan agama, khususnya karya sastra TP. Bahkan TP dapat dianggap merupakan kitab yang penting pada zamannya. Sebab TP sebagai karya sastra yang memberi gambaran tentang kehidupan masyarakat Jawa Kuna zaman Majapahit akhir, khususnya berkaitan dengan kehidupan keagamaan golongan rohaniwan di daerah Kutritusan (Pigeaud, 1924: 128). Golongan tersebut paling domi- 
nan dalam cerita TP. Disebutkan juga golongan rakyat biasa dan empat nama raja. Golongan rakyat biasa terungkap dari jenis pekerjaan yang disebutkan, antara lain sebagai penenun, petani, penjagal, penyadap nira, ahli bangunan, tukang batu, dan lain sebagainya (Pigeaud, 1924: 58, 60).

Penyebutan raja tidak diperlihatkan bentuk pemerintahannya, sebab pemerintahan terpusat pada dewaguru (kepala pertapa) atau pepimpin mandala, terutama di mandala Kukub. Mandala tersebut memiliki bentuk pemerintahan dengan beberapa pejabat tinggi yang diduduki oleh para çisya (murid-murid spiritual) (Pigeaud, 1924: 109). Meskipun tidak terdapat pemerintahan dalam bentuk kerajaan, raja turut mengembangkan kehidupan keagamaan di lingkungannya. Hal itu memperlihatkan bahwa TP merepresentasikan kehidupan keagamaan yang cukup kuat, terutama dari golongan penganut agama Hindu (Siwa) dan Buddha. Masuknya pengaruh Buddha dalam TP tersebut dimungkinkan karena masuknya Hinduisme (Siwaisme) dari India ke Indonesia, khususnya Jawa adalah yang telah mendapat pengaruh ajaran Buddha di India.

Representasi tersebut terwujud dari awal teks TP dengan pemindahan Gunung Mahameru dari Jambudwipa (India) ke Yawadipa (Pulau Jawa). Pemindahan itu memungkinkan terjadinya proses Indianisasi di Pulau Jawa. Mahameru yang dianggap sebagai titik pusat alam semestsa di India dipindahkan ke Pulau Jawa untuk digunakan sebagai poros pengokoh Pulau Jawa. Dwipayana (Bali Post, 21 September 2007) menyatakan bahwa di Jawa telah terjadi proses Indianisasi. Akan tetapi, Dwipayana sendiri menolak pandangannya ketika ia mengajukan tiga catatan penting dari proses Indianisasi tersebut, yaitu:

"pertama, mitos India lebih menjadi fenomena Jawa. Kedua, Indianisasi tidak sepenuhnya berhasil membangun secara totalitas peradaban India karena Indianisasi harus berhadapan dengan fragmentasi paham keagamaan serta masih hidupnya sistem keper- cayaan lokal sebelum Indianisasi berkembang. Oleh karena terjadi pola penerimaan dan pertukaran antara peradaban India dengan lokalitas. Ketiga, Indianisasi sangat terkait dengan bangun kekuasaan politik yang menopangnya. Dengan demikian Indianisasi tidak an sich fenomena kebudayaan melainkan juga fenomena politik."

Catatan tersebut justru mengungkapkan bahwa aspek kebudayaan maupun politik Indianisasi tidaklah berhasil, sebab paham keagamaan dan sistem kepercayaan lokal masih sangat lekat dan kuat mengakar dalam kehidupan masyarakat Jawa. Hal itu didukung oleh realitas yang terjadi dalam masyarakat Jawa dan karya-karya sastra yang berkembang di Jawa bahwa proses Jawanisasi lebih menonjol dibandingkan dengan proses Indianisasi itu sendiri. Terutama dengan Gunung Mahameru dipindahkan dari India, dewa-dewa yang berada di puncak gunung tersebut juga pindah ke Pulau Jawa. Dengan kata lain, proses Jawanisasi sudah terjadi sejak dewa-dewa India menjadi dewa-dewa Jawa (Poerbatjaraka, 1952; Soepomo 1976; Santiko, 1986) disertai dengan perubahan nama gunung Mahameru seperti pada kutipan berikut:

"Uduh kamu kita hyang dewata kabeh, rsigana, çuranggana, widyadara, gandarwwa, laku pareng Jambudipa, tanayangku kita kabeh, alihakna sang hyang Mahameru, parakna ring nusa Jawa, makatitindih paknanya marapwan apageh mari enggangenggung ikang nusa Jawa, lamun tka ngke sang hyang Mandaragiri. Laku, tanayangku kabeh!" (Pigeaud, 1924: 63)

Col andap kulwan, maluhur wetan ikang nusa Jawa; yata pinupak sang hyang Mahâmeru, pinalih mengetan. Tunggaknira hana kari kulwan; matangnyan hana argga Kelâça ngaranya mangke, tunggak sang hyang Mahâmeru ngûni kacaritanya. Pucaknira pinalih mengetan,.... yata ring $P a-$ witra ngaranya mangke pucak sang hyang Mahâmeru kacaritanya ngûni. (Pigeaud, 1924: 65-66)

Dikisahkan bahwa Bhatara Guru memerintahkan para dewa, kelompok resi, perempuan dari surga, para bidadara, makhluk setengah dewa untuk memindahkan Gunung Mahameru dari India ke Pulau 
Jawa, agar Pulau Jawa berhenti bergerak berpindah-pindah. Ketika Mahameru sampai di Pulau Jawa, ditempatkan di ujung barat Pulau Jawa, ujung timurnya menjadi naik. Setengah bagian puncak Mahameru dipindah ke timur, kemudian bernama gunung Pawitra. Adapun pangkalnya tetap tinggal di ujung barat Pulau Jawa disebut Gunung Kelasa. Peristiwa itu menyiratkan bahwa budaya asing yang masuk ke Pulau Jawa perlu menyesuaikan diri dengan keadaan setempat.

Menurut Lestari (1976) gunung Pawitra kini bernama gunung Penanggungan. Gunung tersebut berada di Jawa Timur, tepatnya di Kabupaten Mojokerto. Dalam kepercayaan masyarakat Jawa Gunung Pananggungan merupakan salah satu perwujudan konsepsi makrokosmos karena diyakini sebagai salah satu puncak Mahameru yang dipindahkan oleh dewa penguasa alam. Hingga kini gunung tersebut masih dianggap keramat oleh masyarakat sekitarnya.

Pergantian nama gunung merepresentasikan transformasi budaya India ke Pulau Jawa dengan proses Jawanisasi. Proses tersebut juga terlihat pada saat gunung dipindahkan diadakan penyucian dengan bentuk kisah air wisya (bisa) Kalakuta yang mengakibatkan kematian para dewa menjadi tatwamrta çiwamba (air suci dasar hidup) untuk menghidupkan kembali para dewa (Pigeaud, 1924: 64-65). Kisah tersebut merepresentasikan penyelarasan semesta dari air yang berbisa menjadi air suci, sekaligus penyucian para dewa merupakan gambaran penyucian transformasi budaya yang dibawa serta. Hal itu merepresentasikan pula bahwa secara politik transformasi budaya tidak semena-mena dapat langsung mempengaruhi budaya lokal yang telah mengakar di Pulau Jawa, apalagi titik pusat alam semesta sudah berada di Pulau Jawa.

Peristiwa itu menegaskan bahwa bukan proses Indianisasi yang terjadi, namun sebaliknya proses Jawanisasi terhadap budaya India, seperti kutipan peristiwa berikut:

.... Kunang pwa tan apagih sang hyang Mahâmeru, sumanda ring gunung Brahmâ sira wkasan, apan wyakti rubuh sang hyang Mahâmeru, yan tan sumandaha ring gunung Brahmâ, apan sira goweng sisih iswar. Nimitanira apagěhana ring gunung Brahmâ, rěp mapagěh pangaděg sang hyang Mandaragiri; yata matangnya apagěh tikang nusa Jawa mari molah marayěgan, nisadapagih. Yata matangnyan sang hyang Mahâmeru inaranan gunung Nisada (Pigeaud, 1924: 66).

Mahameru dalam keadaan tidak kokoh karena bagian atasnya ceruk. Setelah disandarkan ke gunung Brahma, gunung yang sudah ada di Pulau Jawa, Mahameru pun dapat berdiri tegak dan Pulau Jawa berhenti bergerak berpindah-pindah. Peristiwa tersebut menyiratkan bahwa Jawa memiliki kekuatan asli yang tersimpan dan tidak kalah dengan kekuatan India. Bahkan Jawa, yang direpresentasikan oleh Gunung Brahma, dapat menyelesaikan persoalan ketika pengaruh India, yang direpresentasikan oleh Gunung Mahameru, menghadapi suatu masalah. Hal itu dimungkinkan adanya politik budaya Jawa untuk memberi pengetahuan dan menyadarkan masyarakatnya bahwa sesungguhnya Jawa sendiri dengan keasliannya telah memiliki akar budaya yang kuat.

Berdasarkan paparan tersebut, terlihat jejak-jejak pengaruh Hindu (Siwa)-Buddha dari transformasi budaya India ke Jawa. Demikian pula penamaan gunung-gunung yang terwujud dari serpihan tanah Gunung Mahameru ketika dipindahkan dari ujung barat ke ujung timur Pulau Jawa, diberi sebutan nama-nama Jawa yaitu Gunung Katong, Wilis, Kampud, Kawi, Arjuna, dan Gunung Kumukus. Sementara itu, pada saat Gunung Mahameru dipindahkan, hadir pula seorang brahmana, Sang Hyang Tkěnwuwung dari India ke Pulau Jawa. Ia melakukan perbuatan diluar tatanan (buang air besar) di aliran sungai dari pegunungan yang mengalir ke daerah Sukayajna (daerah yang lebih rendah). Keadaan sungai itu dikembalikan lagi mengalir ke atas oleh Bhatara Iswara sebagai pendeta (Jawa), hingga air yang bercampur dengan kotoran Sang Hyang Tkěn-wuwung tadi berada di hadapan pemiliknya. Sang Hyang Tkěn-wuwung 
takjub akan kesaktian sang pendeta. Ia mendatanginya, kemudian disucikan dan disempurnakan sebagai seorang wiku di tanah Jawa dengan berganti nama Sidayogi (Pigeaud, 1924: 85-87). Yogi adalah istilah yang dikenal untuk penyebutan untuk para pelaku/pelaksana yoga, pertapa laki-laki; sedangkan pelaku yoga perempuan disebut yogini (Zoetmulder, 2006: 1493).

Kisah tersebut merepresentasikan bahwa pemindahan Mahameru ke tanah Jawa secara tidak langsung disertai masuknya budaya India yang dibawa oleh sang brahmana. Ia menyalahi tatanan masyarakat dan lingkungan setempat (Pulau Jawa), sehingga ia harus menyesuaikan diri dengan budaya atau tatanan setempat. Kisah tersebut menggambarkan hubungan makrokosmos dan mikrokosmos serta akulturasi budaya dalam sebuah keseimbangan yang ditata demi keselarasan kehidupan. Gunung Mahameru sebagai titik pusat alam semesta dan tatanan lingkungan hidup yang diwakili oleh sungai yang mengalir dari daerah pegunungan merupakan makrokosmos.

Manusia yang berada di lingkungan itu berselaras dengan keadaan sekitar agar dapat terus menjaga keseimbangan merupakan gambaran mikrokosmos. Hubungan timbal balik di antara keduanya dapat mewujudkan harmonisasi dalam kehidupan dengan proses akulturasi pada aspek budaya. Proses akulturasi yang terjadi dalam kisah ini adalah penyesuai budaya India terhadap budaya Jawa dalam konsep Siwaistis. Bhatara Iswara sebagai pendeta penganut Siwa memberi kesempurnaan kepada sang brahmana India menjadi wiku Jawa.

Kisah tersebut merepresentasikan bahwa terdapat pengaruh agama yang terbawa dan terbaur dalam kehidupan masyarakatnya dan sekaligus membawa pengaruh politik yang terjadi dalam proses transformasi budaya. Agama Hindu yang bermuatan Buddhisme disesuaikan dengan nilai-nilai dan norma-norma budaya Jawa asli yang telah mengakar kuat di Pulau Jawa. Pengaruh politik yang terjadi diwakili oleh sang brahmana yang disucikan dan disempurnakan menjadi wiku Jawa, serta peng- akuan bahwa pendeta Jawa memiliki kelebihan dibandingkan brahmana dari India. Dengan demikian TP memberikan gambaran sebagai salah satu karya sastra yang merepresentasi kehidupan multikulturalisme normatif dengan masyarakat religius sebagai ciri utamanya dalam wujud sinkretisme. Berikut merupakan gambaran wujud sinkretisme.

\section{Sinkretisme dalam teks TP}

Multikulturalisme yang terdapat dalam teks TP memberi nuansa transformasi budaya yang secara politis merupakan proses Jawanisasi. Nama-nama tokoh dan konsepkonsep yang terdapat di dalamnya merepresentasikan identitas Jawa, Hindu (Siwa), dan Buddha. Ciri masing-masing dapat diidentifikasikan sebagai berikut:

Identitas Jawa selain penyebutan namanama gunung terdahulu, diwujudkan pula pada nama dewa-dewa, terutama namanama penjelmaan Bhatara Guru sesuai dengan peran yang dijalankan di tanah Jawa, antara lain sebagai berikut: pertama, Bathara Jagatpramana, ketika ia sedang pramana 'memperhatikan' jagat 'dunia', yaitu memperhatikan dunia yang kacau dan ia berusaha hendak menatanya kembali.

Kedua, Bathara Jagatnata, ketika ia sedang nata 'menata' (mengatur) jagat 'dunia', antara lain yaitu Bhatara Guru memerintahkan golongan dewa agar membuat tempat tinggal di Yawadipantara (Pulau Jawa dan lain-lain).

Ketiga, Bathara Mahakarana, ketika ia melanjutkan memerintahkan para dewa untuk mencipta berbagai jenis pekerjaan di Pulau Jawa (sebagai pandai besi, pandai emas, ahli bangunan, pelukis, guru) dengan perangkat, sarana dan prasarana yang digunakan atau dikenakan oleh manusia (alat pertukangan, membangun rumah, membuat perhiasan, lukisan, tenunan untuk pakaian) serta memerintahkan agar para dewa mencari pengokoh Pulau Jawa yang masih bergoyang.

Keempat, Bathara Nilakanta, ketika ia menguji air bisa Kalakuta yang keluar dari gunung Mahameru dan mengakibatkan ke- 
matian para dewa, hingga membuat leher menjadi hitam akibat minum air yang beracun dan diubahnya air menjadi tatwamrta çiwamba "air suci dasar hidup" dan seterusnya.

Kelima, Bhatara Parameswara, ketika ia melanjutkan membuat tempat-tempat suci/ mandala di pulau Jawa.

Paparan tersebut mengungkapkan bahwa penyebutan nama-nama Bhatara Guru disesuaikan dengan gambaran peran yang diemban selama berada di tanah Jawa. Demikian pula, banyak mitos tentang dewadewi yang tidak pernah didengar di India dijumpai di Jawa, misalnya Hyang Kandyawan, Sang Mangukuhan, Sang Sandang Garba, Sang Katung Malaras, Sang Karung Kalah, Sang Wreti Kandayun, Bhatari Smari, Sang Hyang Ktěk-mělěng dan lain-lain. Nama Sang Hyang Kamandalu berisi tatwâmrta çiwâmbha (Pigeaud, 1924: 66). Orang Majapahit dengan sadar menciptakan dewa-dewi baru, dan dalam karya sastra, khususnya TP secara implisit disebut perubahan terjadi karena "dewa-dewa Jambhudwipa telah menjadi dewa-dewa Jawa."

Peristiwa pemberian nama tersebut secara eksplisit dikisahkan pula pada ketiga anak batari Uma yang lahir dari hasil persenggamaannya dengan Bhatara Guru yang menyamar menjadi anak gembala sapi betina hitam. Proses pemberian nama dengan upacara pentahbisan dan penobatan peran mereka masing-masing seperti berikut:

..., yata matangnya pinratisthanira tang raray wkasan:

“.... Kunang kita sang matuhâ, dak sangaskara kita, ..., tinhir mpu Kumara-gimbal ngaranta, wiku rsyangarěmban ta ngaranta mangke. ...."

"Kunang kita raray panngah, dak sangaskara kita, ..., tinhěr mpu Kumâra-siddhi ngarananta. ..., matangnya wiku çewa ngaranta ring rât. Warahwarah tang mânusa ring aksara wijjâna, kita jastapadasâri ning bhuwana. ..., tinhěr mpu Bhujangga ngarananta...."

"Kunang kita raray pamungçu, dak sangaskara kita mangke, mpu Kumara-raray ngaranta; ...; wiku boddha ta ngaranta ring rât, pamindha kita ring bhatâra Buddha dlahâ. ..., tinhěr ta çogata ngaranta ring rât ...." (Pigeaud, 1924: 79).
Pentahbisan dan penobatan ketiga anak tersebut merupakan anugerah Bhatari Uma kepada mereka untuk turut membantu menyempurnakan bumi dan manusia Jawa agar menyadari keluhuran budayanya. Anak pertama diberi nama mpu Kumaragimbal dengan julukan resi Angrěmban sebagai biku atau orang suci yang siap menjalankan tugasnya. Anak kedua diberi nama mpu Kumara-siddhi dengan julukan di bumi sebagai biku penganut Siwa yang diberi tugas mengajar manusia akan aksara wijjâ$n a$, sehingga mendapat gelar mpu Bhujangga 'jabatan keagamaan saiwa atau boddha' (Zoetmulder, 2006: 139). Anak yang bungsu diberi nama mpu Kumara-raray dengan julukan di bumi sebagai pertapa boddha dan bergelar Sogata yang kelak akan menyerupai Bhatara Buddha.

Peristiwa tersebut merepresentasikan secara eksplisit bahwa TP bermuatan Buddhisme bersama masuknya pengaruh Hinduisme yang bersifat Siwaistis ke Pulau Jawa. Apabila dilihat secara historis, masuknya budaya asing yang membawa serta agama atau kepercayaan tersebut, diikuti lahirnya dan berkembangnya suatu aliran, dapat dipastikan terjadi interaksi dengan kepercayaan lokal pada saat itu. Interaksi tersebut menyebabkan paham keagamaan/ kepercayaan yang terwujud tidak sepenuhnya bertahan dalam bentuk aslinya, melainkan mengalami proses silang budaya dengan kepercayaan lokal. Kepercayaan tersebut dalam TP disebutkan dengan çaiwa sogata (penganut agama Siwa dan penganut agama Buddha) sebagai bentuk sinkretisme yang nyata. Representasi tersebut akan disampaikan pada pembahasan identitas masing-masing berikut ini.

Identitas Hindu (Siwaistis) sudah dapat dipastikan dengan sebutan nama Bhatara Guru itu sendiri yang merupakan penjelmaan Siwa. Bhatara Guru adalah nama lain Siwa yang sedang berperan sebagai guru atau pendidik (Siwa yang sedang memberikan pelajaran di dunia). Sementara itu, Siwa sendiri dikenal sebagai dewa agama Hindu yang sangat penting di India. Dalam tulisan Siwa in Java: The Majestic Great God and the 
Teacher pada Ars Orientalis dinyatakan bahwa:

Siwa the teacher is Siwa Bhatara Guru (Lord Teacher), that is, Siwa when one thinks of him as teacher....-realities, incidentally, that are inner, accessible through meditation practice, centered on one's own body. A manifestation of Siwa rule over each reality, and Bathara Guru is Siwa manifesting himself in the visible reality.... Thus Siwa is Bhatara Guru as he is simultaneously Mahadewa, Sadasiwa, as he is also Sang Paramartha (The Highest).....

In my view, the category of Siwa the Teacher ought to comprise such images, mostly from Centra Java, especially Dieng .... They represent Siwa seated in a meditative posture ....(Royo, 2003: 188-189)

Peristiwa pada kutipan tersebut, juga terdapat pada awal cerita TP ketika Bhatara Guru hendak menyelamatkan Pulau Jawa yang masih bergoyang ke sana ke mari, sebelum ia memerintahkan Hyang Brahma dan Wisnu menciptakan manusia di Pulau Jawa (Pigeaud, 1924: 57). Hal itu mengungkapkan bahwa nama-nama tersebut sebagai identifikasi dari peran yang sedang dilaksanakan oleh tokohnya (Bhatara Guru). Secara garis besar, dapat dikatakan bahwa dalam lingkungan kepercayaan masyarakat pemilik cerita tersebut, budaya Jawa, penyebutan nama dianggap penting sebagai salah satu ciri perannya di dunia ini. Oleh karena itu, perubahan atau pergantian peristiwa ke peristiwa dalam cerita dapat diikuti dari identifikasi perbedaan atau pergantian penyebutan nama yang disebutkan.

Identitas Buddha lebih pada konsepkonsep ajaran yang disampaikan penulis/ penyalin TP. Misalnya, seperti adanya ajaran pañcaçiksa/pancasila sebagai dasar tingkah laku manusia yang hendak mencapai kesempurnaan hidupnya diberi aturan-aturan agar senantiasa bersih menjalankan kehidupannya secara moral. Pancasila Buddha berisi: (1) saya berjanji untuk tidak melakukan pembunuhan; (2), saya berjanji untuk tidak melakukan pencurian; (3) saya berjanji untuk tidak melakukan perjinahan; (4) saya berjanji untuk tidak berbohong; (5) saya berjanji untuk tidak meminum segala sesuatu yang memabukkan, yang melemahkan kesadaran saya (Majubuthi, 2000-2010, dalam http://www.walubi.or.id/wacana/wacana_ $d w_{-}$77.shtml).

Setelah aturan-aturan itu secara intens dilaksanakan dalam kehidupan sehari-hari, untuk meningkatkan kesempurnaannya lebih lanjut diberi pula ajaran yang bersifat lebih mendalam dengan melaksanakan daçaçila/dasasila Dasasila Buddha: (1) Aku bertekad untuk melatih diri menghindari pembunuhan; (2) aku bertekad untuk melatih diri menghindari mengambil barang yang tidak diberikan; (3) aku bertekad untuk melatih diri menghindari perbuatan asusila; (4) aku bertekad untuk melatih diri menghindari ucapan yang tidak benar; (5) aku bertekad untuk melatih diri menghindari segala minuman keras yang dapat menyebabkan lemahnya kesadaran; (6) aku bertekad untuk melatih diri menghindari makan makanan setelah tengah hari; (7) aku bertekad untuk melatih diri menghindari untuk tidak menari, menyanyi, bermain musik serta pergi melihat tontonan-tontonan; (8) aku bertekad untuk melatih diri menghindari pemakaian bunga-bungaan, wangi-wangian, dan alat kosmetik untuk tujuan menghias dan mempercantik diri; (9) aku bertekad untuk melatih diri menghindari penggunaan tempat tidur dan tempat duduk yang tinggi dan mewah; (10) Aku bertekad untuk melatih diri menghindari menerima emas dan perak (uang). (Indoforum Junior E, 2006 dalam http://www. indoforum.org/showthread.php? $t=28123$ ), dan pañcagati sangsara. Pancagati sangsara adalah ajaran 'lima tingkat penjelmaan dalam rangka lingkaran lahir kembali': manusia disucikan menjadi wiku; wiku menjalankan tapa dan bersujud menjadi para dewa; para dewa akan menanjak menjadi golongan hyang; dan golongan hyang akan naik menjadi sidaresi, dan akhirnya sidaresi dapat mencapai golongan batara. Dalam ajaran Buddhisme diharapkan manusia dapat mencapai pelepasan diri dari pancagati sangsara tersebut untuk menjadi manusia sempurna. (Pigeaud, 1924: 83) 
Dikisahkan bahwa pencapaian kesempurnaan manusia dilakukan dengan pañcagati sangsara sebagai pelepasan diri melalui lima tingkat penjelmaan dalam rangka lingkaran lahir kembali, seperti kutipan berikut:

\section{Mojar ta bhatâra Guru:}

"Kapan ta kang manusa limpada sakeng pañcagati sangsara? Dawning makâryya mandala panglpasana pitarapâpa. Antuk aning manusa mangaskara hayun wikuha; matapa sumambaha dewata, dewata suměngkaha watěk hyang, watěk hyang suměngkâha siddârsi, siddârsi suměngkâha watěk bhatâra. Lena sakerikâ hana pwa wiku sasar tapabratanya; tmahanya tumitis ing rât, mandadi ratu cakrawarthi wiçesa ring bhuwana, wurungnya mandadi dewata. Matangnyan wuwurungan dewata prabhu cakrawarthi, apan tmahan ing wiku sasar tapabratanya hika. Matangnyan ta kita, hyang Wisnu, pangaskârani kanyu!" (Pigeaud, 1924: 83)

Dalam ajaran Hindu (Siwa), konsep tersebut dikenal dengan sebutan reinkarnasi sebagai kelahiran kembali sesuai dengan karma manusia, sedangkan dalam ajaran Buddha pelepasan diri manusia mencapai nirwana melalui dharma. Dalam setiap kenaikan tingkatan tapa itu, masing-masing harus melalui pensucian kembali hingga di akhir pencapaian menjadi Bhatara. Tingkat Bhatara dapat dicapai bagi seseorang yang telah melepaskan diri dari segala sesuatu yang bersifat duniawi. Proses tersebut merupakan pelepasan diri dari kesengsaraan untuk mencapai kebahagiaan abadi. Dalam ajaran Buddha dikenal Samsara adalah titik pencapaian satu kesatuan kesadaran antara makrokosmos dan mikrokosmos, yaitu nirwana: awareness of this that constitutes both his enlightenment dan his moksa. Everything, to use a different terminology, is the product of the One Mind (bhutatathata), the microcosmos is the macrocosmos, Nirvana is Samsara, there is no duality (Johns, 1966: 40). Dengan demikian dapat diketahui bahwa konsep pañcagati sangsara itu merupakan ajaran yang berasal dari agama Buddha.

Di lain pihak, identitas Hindu (Siwa)Buddha telah melebur dalam satu kesatuan wujud yang direpresentasikan oleh Mpu Mahapalyat, seorang pendeta penganut Siwa (çaiwapaksa), kemudian membagi dua dirinya menjadi çaiwa sogata (penganut agama Siwa-Buddha) ke dalam tokoh Mpu Bharang yang menganut agama Siwa dan $\mathrm{Mpu}$ Waluh-bang yang menganut agama Buddha. Selanjutnya kedua tokoh tersebut berpencar untuk mencari penganut masingmasing. Mpu Bharang menuju arah timur dan Mpu Waluh-bang menuju arah barat Pulau Jawa (Pigeaud, 1924: 109, 112). Dengan kata lain, Mpu Mahapalyat merupakan tokoh yang merepresentasikan satu kesatuan Hindu (Siwa)-Buddha yang bertugas menyebarkan agama.

Berdasarkan bahasan tersebut, dapat dikatakan bahwa TP merepresentasikan terjadinya sinkretisme Hindu (Siwa)-Buddha secara damai dan mengadakan penyesuaian dengan budaya setempat, yaitu budaya Jawa. Peristiwa tersebut telah didahuli oleh tindakan para resi ketika mendirikan pusatpusat pendidikan agama yang dikenal sebagai mandala atau kadewaguruan. Bhatara Parameçwara (Bhatara Guru) sebagai pendiri tempat suci atau mandala pertama kali di Pulau Jawa, mengenakan pakaian lengkap disertai ikat/iket. Iket (dhestar) yaitu kain segi tiga yang dipakai untuk menutup kepala dengan ditata sedemikian rupa (Poerwadarminta, 1939: 168).

Ia langsung menduduki takhta di daerah tersebut dan bertindak sebagai dewaguru beruturt-turut di mandala Sarwasida, Sukawela, dan Sukayajna. Bagi orang Jawa, pakaian lengkap dan iket merupakan persyaratan yang harus dikenakan ketika melaksanakan kegiatan atau aktivitas resmi, seperti ritual-ritual keagamaan, adat atau kenegaraan. Adapun tujuan mandala dibuat adalah sebagai tempat pembebasan leluhur yang telah mencapai kesempurnaan (pelepasan diri/moksa) (Pigeaud, 1924: 81-82).

Pada masa setelah Hayam Wuruk jumlah kedewaguruan kian banyak dan menjadi pusat percampuran budaya Hindu (Siwa)Buddha dan budaya Jawa. TP pun menyebutkan nama-nama tempat tersebut dari 
mandala pertama dibangun, mandala Sarwasida hingga yang terakhir mandala Hahah. Mandala-mandala tersebut berada di sekitar Gunung Mahameru (Pawitra). Pembangunan selanjutnya adalah dari masingmasing para suci yang telah menerima wewenang dari Bhatara Guru.

Di samping itu, TP memiliki rahasia air kehidupan, seperti telah disebutkan terdahulu, sebagai air suci dasar hidup yang merupakan sumber kehidupan golongan dewa dan seluruh makhluk, serta alam semesta.

Kahucapa ta sang watěk dewata kabeh, pada kengelan sira mamutěr i sang hyang Mandaragiri, yata sira pada malapa way. Ana ta way mijil saking sang hyang Mahâmeru, wai wisya Kalakûta ngaranya; ...; sangka ring helning dewata kabeh tinahapnira tang wai wisya Kâlakûta. Nhìr pjah ta sang dewata kabeh dening çakti nikang wai wisya Kâlakûta ngaranya. Mulat sira bhatâra Parameçwara:

"I, pjah kita sang dewata kabeh; ah mapa nimitanya pjah kabeh arih? Ih, umisnikang gunung, pilih ininumnya, matangnyan pjah kabeh. Ah, uh, dak tahapnya."

Tinahapnira tang wai Kalakûta; mahirěng gulu bhatâra kadi twah rûpanya. Matangnyan bhatâra Guru mangaran bhatâra Nilâkanta, apan ahirěng kadi twah. Mojar ta bhatâra Guru:

"Ih, mahâçakti dahat ngko arih; kasakitan aku denya."

Rěp dinělěngnira tang wai wisya Kâlakûta, yata matmahan tatwâmrtha çiwâmba. Yata pinakaisi sang hyang Kamandalu, pinakapaniramnira ri sang dewata kabeh. Jag lěs pwa sumiram sang hyang tatwâmrta çiwâmbha ri sang dewata kabeh; yata mahurip sira kabeh mwang caturlokaphala, widyadara, gandarwwa, pada sumambah ri bhatâra Guru sang dewata kabeh. .... (Pigeaud, 1924: 6465)

Air tersebut keluar dari Gunung Mahameru pada saat proses dipindahkan ke Pulau Jawa. Wisya Kalakûta merupakan air bisa/racun dan memiliki kesaktian yang luar biasa, sehingga mengakibatkan kematian bagi yang meminumnya, golongan dewa maupun bhatara, seperti yang terjadi pada Bhatara Guru. Oleh karena itu, Bhatara Guru segera bertindak mengubah air tersebut menjadi tatwâmrta çiwâmbha (air suci dasar hidup) yang dapat menghidupkan kembali para dewa, bahkan menjadi sumber kehidupan abadi seluruh alam semesta. Peristiwa tersebut merepresentasikan bahwa manusia yang telah mencapai tingkat dewa maupun bhatara sekalipun, senantiasa harus menjaga kesadaran akan hadirnya pengaruh dari luar dirinya. Jika dalam ketidaksadaran akan berakibat fatal bagi diri dan lingkungannya. Air sebagai sumber hidup dan kehidupan yang datangnya dari tempat asing perlu disucikan dan diselaraskan dengan daerah setempat.

Apabila dipandang dari aspek budaya dapat dikatakan sebagai sebuah peringatan bahwa segala pengaruh yang datangnya dari luar, dalam hal ini India, hendaknya diwaspadai dan diselaraskan terlebih dahulu dengan budaya lokal, Jawa. Dapat pula dikatakan bahwa kisah ini merepresentasikan tentang manusia Jawa dengan budaya dan sistem kepercayaan yang lebih tinggi tingkat kemurniannya dibandingkan budaya yang mempengaruhinya. Sebab budaya yang masuk, agama atau sistem kepercayaan beserta ajaran, senantiasa berusaha keras untuk menyesuaikan diri agar dapat bersatu dengan budaya Jawa. Dengan kata lain, perubahan sinkretik yang terdapat dalam karya sastra TP, tidak semata-mata terjadi begitu saja. Akan tetapi membutuhkan penyesuaian dengan lokal genius dalam kehidupan multikultur di Pulau Jawa.

Di sisi lain, manusia Jawa sendiri memiliki pedoman hidup nampa lan tampa (menerima dan dapat mengerti/paham) terhadap segala aspek kehidupan, sehingga dengan mudah bersikap toleran terhadap budaya asing yang masuk. Bahkan dapat menyatukan keragaman budaya yang mengalir dalam kehidupan tanpa sebuah persaingan dan pertentangan. Proses Jawanisasi juga terjadi secara halus, sehingga dapat dengan cepat meresap dalam kehidupan masyarakat.

Dengan demikian dapat dinyatakan bahwa TP sebagai teks yang memuat multiagama dan multibudaya sebagai sinkretis- 
me dari budaya Jawa, Hindu (Siwa), dan Buddha. TP merupakan teks yang memberikan pengetahuan sinkretisme yang terwujud secara damai dalam kehidupan religiusitas masyarakat Jawa, sehingga identitas yang bersifat Jawa, Hindu (Siwa), dan Buddha dapat berpadu dalam satu kesatuan tindakan keseharian masyarakat Jawa, khususnya di daerah karang kapunjanggan, Kutritusan.

\section{SIMPULAN}

Representasi yang terungkap dari teks TP merupakan implementasi dari sinkretisme Jawa, Hindu (Siwa) dan Buddha, dan ketiganya berada dalam hubungan yang mutualistik. Dalam sebagian besar isi cerita nampak yang dominan adalah Hinduisme/ Siwaisme. Akan tetapi secara tersirat konsep-konsep ajaran Buddha lebih menonjol dan Jawa dengan budaya aslinya dapat menyatukan kesejajaran multiagama dan multikultur tersebut dengan nilai-nilai dan norma-norma universal dalam kehidupan spiritual masyarakatnya.

Demikian pula, seperti halnya yang dialami oleh agama-agama lain, Hinduisme/ Siwaisme mengalami tarik-menarik antara ide universalitas dan lokalitas, serta antara pendekatan purifikasi dan pendekatan budaya. Sejarah agama-agama besar penuh dengan cerita gerakan purifikasi yang menjadi bagian yang tidak terpisahkan dari dialektika keagamaan dan relasi kuasa. Akan tetapi dengan terkuaknya sinkretisme yang terdapat dalam karya sastra TP dapat dikatakan bahwa keadaannya tidak demikian. Perwujudan tersebut sangat tampak pada saat Gunung Mahameru dipindahkan dari Jambudwipa ke Yawadipa. Secara tidak langsung, budaya, agama, dan politik terbawa dalam proses pemindahan itu dan dapat diterima dengan tangan terbuka oleh budaya Jawa.

Salah satu tujuan TP ditulis atau diciptakan adalah untuk menyampaikan pengetahuan tentang sebuah konsep ajaran, baik Jawa, Hindu (Siwa), Buddha yang dapat diterima dalam kehidupan budaya spiritual masyarakat sebagai wujud tindakan manusia. Adapun wujud tindakan itu merupakan gambaran masyarakat yang terdapat dalam karya sastra TP dan mengacu pada masyarakat Jawa Kuna zaman Majapahit akhir. Dengan demikian, sinkretisme yang terdapat di dalam karya sastra TP bersifat positif dan tetap dapat diterima sebagai sesuatu yang berharga dari warisan budaya Indonesia, sehingga patut dipelajari lebih dalam untuk dipetik manfaatnya. Bahkan dapat pula sebagai sumbangan yang bermakna bagi perkembangan dinamika kebudayaan di Indonesia.

\section{DAFTAR PUSTAKA}

Dwipayana, A. A., 2007, "Mitos Indianisasi," Bali: Bali Post, 21 September 2007.

Endraswara, S., 2006, Mistik Kejawen: Sinkretisme, Simbolisme, dan Sufisme dalam Budaya Spiritual Jawa, Cetakan keempat, Yogyakarta: Penerbit Narasi.

Johns, A.H., 1966, “From Buddhism to Islam: an Interpretation of the Javanese Literature of the Transition Author. Comperative Studies in Society and History." No. 1, Vol. 9, 40-50, Cambridge: Cambridge University Press. http://www.jstor.org/stable/177836

Lestari, N., 2005-2009, Swarloka di Gunung Pananggungan, Malang: IMPALA UNIBRAW dalam www. impalaunibraw.or.id/artikel/25lingkungan/14-swarloka di gunung pananggungan.html-22k. 29 Mei 1976.

Marjani, G. I., 2009, “Multikulturalisme dan Pendidikan: Relevansi Pendidikan dalam Membangun Wacana Multikulturalisme di Indonesia," Makalah yang disajikan pada the $9^{\text {th }}$ Annual Conference on Islamic Studies di Surakarta. 2-5 November 2009.

Munandar, A. A., 1990, “Kegiatan Keagamaan di Pawitra: Gunung Suci di Jawa 
Timur Abad 14-15." Tesis, Depok: Fakultas Pascasarjana UI.

Parekh, B., 2008, Rethinking Multiculturalism, Keberagaman Budaya dan Teori Politik. Judul asli: Rethinking Multiculturalism. Cultural Diversity and Political Theory., Cetakan kelima. Diterjemahkan oleh C.B. Bambang Kukuh Adi. Yogyakarta: Kanisius.

Pigeaud, T. G. T., 1924, De Tantu Panggelaran. Nederland:'s - Gravenhage, Boek en Steendrukkerif voorheen $\mathrm{H}$ L Smits.

Poerbatjaraka, R.M.Ng., 1952, Kapustakan Djawi. Jakarta: Djambatan.

Royo, A. L. Y., 2003. Siva in Java: The Majestic Great God and the Teacher. Ars Orientalis, Vol. 33, 180-196. Michigan: Freer Gallery of Art. The Smithsonian
Institution and Departement of the History of Art, University of Michigan dalam http://www.jstor.org/stable/ 4434277

Santiko, H., 2009, "Majapahit, Suram Sinarmu," Jakarta: Kompas. 14 Januari 2009.

Sedyawati, E., 2001, “Tantu Panggelaran Dan Manikmaya: Bandingan Kosmogoni," Seminar Jawa Kuno di FIB UI, Jakarta: UI.

Suyono, A., 1985, Kamus Antropologi. Jakarta: Akademika presindo.

Widyadharma, P. S., 1999, Intisari Agama Buddha, Jakarta: Cetiya Vatthu Daya. 